\title{
Skin Autofluorescence, as a Measure of AGE Accumulation in Individuals Suffering from Chronic Plaque Psoriasis
}

\author{
Karolina Kopeć-Pyciarz, ${ }^{1}$ Irena Makulska, ${ }^{2}$ Danuta Zwolińska, ${ }^{2}$ Lukasz Laczmański, ${ }^{3}$ \\ and Wojciech Baran (iD) \\ ${ }^{1}$ Department of Dermatology, Venereology and Allergology, Wroclaw Medical University, Poland \\ ${ }^{2}$ Department of Paediatric Nephrology, Wroclaw Medical University, Poland \\ ${ }^{3}$ Institute of Immunology and Experimental Therapy, Polish Academy of Sciences, Poland
}

Correspondence should be addressed to Wojciech Baran; wojciech.baran@umed.wroc.pl

Received 7 June 2018; Accepted 26 August 2018; Published 27 September 2018

Academic Editor: Calogero Caruso

Copyright (c) 2018 Karolina Kopeć-Pyciarz et al. This is an open access article distributed under the Creative Commons Attribution License, which permits unrestricted use, distribution, and reproduction in any medium, provided the original work is properly cited.

\begin{abstract}
Background. Psoriasis is currently regarded as a chronic systemic inflammatory disease associated with increased cardiovascular risk. Advanced glycation end products (AGEs) contribute to the development of atherosclerosis. Objectives. The aim of the study was the assessment of skin autofluorescence (SAF), as a measure of AGE accumulation, in individuals suffering from chronic plaque psoriasis without any comorbid conditions. Methods. A study group consisted of 70 patients with chronic plaque psoriasis without any comorbid conditions and 59 healthy controls, matched by age and gender. AGE accumulation was assessed by SAF (AGE Reader, DiagnOptics BV) which is a validated and noninvasive technique. Relations between SAF and some clinical and laboratory data were assessed. Results. SAF was positively correlated with age both in patients with psoriasis and controls $(R=0.722, p<0.00001$ and $R=0.613, p<0.00001$, respectively). There was significantly increased SAF in patients with psoriasis with elevated levels of C-reactive protein (CRP) and increased erythrocyte sedimentation rate (ESR) compared to controls $(p<0.00001 ; p<0.00001$, respectively, after adjustment to age). Increased SAF was found in psoriatic patients with prediabetes (HbA1c 5.7-6.4\%) compared to controls ( $p<0.0012$, after adjustment to age). Conclusion. Systemic inflammation (increased CRP level), prediabetes, and aging may influence enhanced AGE accumulation in patients with psoriasis without any comorbidities. SAF may be considered as a useful, noninvasive method to identify patients with psoriasis at increased cardiovascular risk.
\end{abstract}

\section{Introduction}

Psoriasis is a chronic, relapsing immune-mediated inflammatory disease of the skin that affects approximately $2 \%$ of the population worldwide. The growing number of evidence indicates that psoriasis is a chronic systemic inflammatory disease associated with increased cardiovascular risk.

Advanced glycation end products (AGEs) are a group of heterogeneous compounds formed by endogenous nonenzymatic glycation and oxidation (glycoxidation) of proteins, lipids, and nucleic acids [1-4]. Accumulation of AGEs increases in chronic hyperglycemia and also in oxidative stress associated with chronic inflammation. Increased formation and accumulation of AGEs have been found in diabetes, chronic renal failure, and some chronic immunemediated inflammatory diseases, such as rheumatoid arthritis [3-8]. A chronic inflammatory process may lead to the oxidative stress and formation of reactive carbonyl compounds that may be partly transformed to AGEs [1-3]. It has been shown that accumulation of AGEs is associated with accelerated atherosclerosis and vascular complications [3, 4, 6-9]. AGE accumulation in an extracellular matrix results in increased rigidity and reduced elasticity of the vascular wall [2-4]. Furthermore, interactions of AGEs with receptor for advanced glycation end products (RAGE) have been shown to be implicated in the development of endothelial dysfunction and atherosclerosis [3, 9-11]. AGEs acting through RAGE induce activation of intracellular signaling 
TABLE 1: Clinical and demographic characteristics of the study group.

\begin{tabular}{|c|c|c|}
\hline Characteristic & $\begin{array}{c}\text { Patients with } \\
\text { psoriasis }(n=70)\end{array}$ & $\begin{array}{l}\text { Controls } \\
(n=59)\end{array}$ \\
\hline Mean age \pm SD (range) years & $49.33 \pm 17.95$ & $47.41 \pm 14.11$ \\
\hline Male $n(\%) /$ female $n(\%)$ & $35(50 \%) / 35(50 \%)$ & $\begin{array}{l}29(49.15 \%) / \\
30(50.84 \%)\end{array}$ \\
\hline $\mathrm{BMI}$ mean $\pm \mathrm{SD}$ & $26.12 \pm 3.39$ & $25.22 \pm 2.62$ \\
\hline PASI mean \pm SD & $10.85 \pm 6.57$ & \\
\hline BSA $(\%)$ mean \pm SD & $23.28 \pm 15.44$ & \\
\hline
\end{tabular}

pathways leading to enhanced production of proinflammatory cytokines, adhesion molecules, vasoconstriction, and coagulation [11].

AGE accumulation can be assessed by skin autofluorescence (SAF) following the principles of AGE Reader, which is a validated and noninvasive technique. SAF measured by AGE Reader significantly correlates with specific AGEs, such as pentosidine, $\mathrm{N}$-(carboxymethyl)-lysine (CML) and $\mathrm{N}$ (carboxyethyl) lysine (CEL), in skin biopsies [3, 4, 12-15]. Increased SAF has been shown to be associated with vascular complications and was an independent predictor of cardiovascular morbidity and mortality in patients with diabetes, chronic renal failure, and cardiovascular diseases [4, 16-23]. Furthermore, SAF was related to arterial stiffness and the insulin level in healthy population [24, 25].

The objective of the present study was the assessment of $\mathrm{SAF}$, as a measure of AGE accumulation, in individuals suffering from chronic plaque psoriasis. To evaluate the effect of psoriasis on AGE accumulation more precisely, we excluded from the study psoriatic patients with comorbid conditions associated with enhanced AGE accumulation, such as diabetes, dyslipidemia, chronic renal failure, cardiovascular diseases, and smoking habit. Furthermore, we assessed relations between SAF and the severity of skin involvement, level of C-reactive protein (CRP), erythrocyte sedimentation rate (ESR), body mass index (BMI), age, gender, levels of LDL, and levels of glycated hemoglobin (HbA1c).

\section{Materials and Methods}

2.1. Study Group. The study group consisted of 70 patients with chronic plaque psoriasis and 59 healthy controls, matched by age and gender. Subjects underwent clinical and demographic evaluations at the time of recruitment (Table 1). All patients and controls were Caucasians. Patients did not receive any systemic therapy or phototherapy at least 8 weeks prior to the initiation of the study. Severity of disease was assessed by using Psoriasis Area and Severity Index (PASI) and body surface area (BSA). The patients did not have psoriatic lesions on the inner surface of at least one forearm. 49 patients had type I psoriasis ( 25 women and 24 men) and 21 type II psoriasis (10 women and 11 men). From each subject, approximately $15 \mathrm{ml}$ of blood was taken for laboratory tests (complete blood count, lipid profile, fasting glucose, glycated hemoglobin (HbAlc), C-reactive protein (CRP), and erythrocyte sedimentation rate (ESR)). Exclusion criteria included cardiovascular disease (defined as history of coronary artery disease, myocardial infarction, stroke, and chronic heart failure), chronic renal or liver disease, diabetes mellitus, malignancies, dyslipidemia, smoking habit, and uncontrolled hypertension. Subjects who reported smoking at least one cigarette per day during the last year were classified as smokers. Dyslipidemia was defined as an elevated level of triglyceride and total or low-density lipoprotein (LDL) cholesterol. Body mass index (BMI) was calculated as the ratio of weight $(\mathrm{kg})$ to height $(\mathrm{m})$ squared $\left(\mathrm{kg} / \mathrm{m}^{2}\right)$. According to WHO criteria, subjects with $\mathrm{BMI} \geq 30$ were considered as obese. The study was approved by the local bioethical committee according to Helsinki Declaration.

2.2. Skin Autofluorescence. Noninvasive measurement of skin autofluorescence (SAF) was assessed by AGE Reader, DiagnOptics BV (Groningen, the Netherlands), according to the guidelines [12]. Approximately $4 \mathrm{~cm}^{2}$ of the skin of the ventral site of the lower arm, protected from surrounding light, in room temperature was illuminated with a wavelength of 300-420 nm. Measurements were performed at uninvolved skin to prevent influences by the presence of skin lesions. Emission light and reflected excitation light were measured with a spectrometer (AVS-USB2000; Avantes, Eerbeek, the Netherlands). The autofluorescence was calculated by dividing the mean emitted intensity per $\mathrm{nm}$ by the mean reflected excitation intensity and expressed in arbitrary units (AU). The SAF value is calculated by automated analysis. Results are mean values of three measurements performed for each patients [12]. Laboratory tests were performed using standard assays.

2.3. Statistical Analysis. The results were statistically analyzed using the computer program Statistica 13.0 (Windows 10) and GraphPad Prism version 5.0. The mean, median, maximal, minimal, and standard deviations of values were calculated. Student's $t$-test (for normally distributed data) or Mann-Whitney $U$ test (for not normally distributed data) were used to analyze continuous variables. Data was adjusted to age. The significance of differences between categorical variables was determined by the Pearson Chi-square test, Chi-square with Yates correction test, or Fisher's exact test. The relations between continuous variables of interest were assessed by Spearman's rank correlation coefficient. Statistical significance was set at $p<0.05$.

\section{Results}

Detailed characteristics of patients with psoriasis are shown in Table 2. We found significant positive correlations between SAF and age both in patients with psoriasis and controls $(R=0.722, p<0.00001 ; R=0.613, p<0.00001$, respectively) (Figure 1). There was no statistically significant difference in SAF values between the whole group of patients with psoriasis and controls $(1.887 \pm 0.6$ vs. $1.816 \pm 0.38)$. The mean \pm SD value of CRP in patients with psoriasis was $5.96 \pm 9.79 \mathrm{mg} / \mathrm{dl}$, and 19 patients had elevated levels of CRP (CRP $>5 \mathrm{mg} / \mathrm{dl}$, according to the local laboratory). There was significantly increased SAF in psoriatic patients 
TABLE 2: Characteristics of patients with chronic plaque psoriasis.

\begin{tabular}{|c|c|c|c|c|c|c|c|c|}
\hline Characteristic & $\operatorname{PsV}(n=70)$ & $\begin{array}{l}\text { PsV type I } \\
(n=49)\end{array}$ & $\begin{array}{l}\text { PsV type II } \\
(n=21)\end{array}$ & $\begin{array}{c}\text { PsV with } \\
\text { elevated } \\
\text { CRP } \\
(n=19)\end{array}$ & $\begin{array}{c}\text { PsV with } \\
\text { increased } \\
\text { ESR } \\
(n=34)\end{array}$ & $\begin{array}{c}\text { PsV with } \\
\text { borderline } \\
\text { LDL } \\
(n=16)\end{array}$ & $\begin{array}{l}\mathrm{PsV} \text { with } \\
\text { prediabetes } \\
(n=21)\end{array}$ & $\begin{array}{l}\text { Controls } \\
(n=59)\end{array}$ \\
\hline SD (years) & $49.33 \pm 17.95$ & $42.92 \pm 16.13$ & $63.55 \pm 11.93$ & $54.79 \pm 18.96$ & $54.43 \pm 16.38$ & $52.50 \pm 13.21$ & $57.95 \pm 11.55$ & $47.05 \pm 13$ \\
\hline $\begin{array}{l}\text { Male } n(\%) / \\
\text { female } n(\%)\end{array}$ & $\begin{array}{l}35(50 \%) \\
35(50 \%)\end{array}$ & $\begin{array}{l}24(48.97 \%) \\
25(51.03 \%)\end{array}$ & $\begin{array}{l}11(52.39 \%) \\
10(47.61 \%)\end{array}$ & $\begin{array}{c}10(52.63 \%) \\
9(47.37 \%)\end{array}$ & $\begin{array}{l}16(47.05 \%) \\
18(52.95 \%)\end{array}$ & $\begin{array}{l}7(43.75 \%) \\
9(56.25 \%)\end{array}$ & $\begin{array}{l}10(47.61 \%) \\
11(52.39 \%)\end{array}$ & $\begin{array}{l}29(49.1 \%) \\
30(50.8 \%)\end{array}$ \\
\hline PASI mean \pm SD & $10.85 \pm 7.07$ & $11.02 \pm 6.43$ & $10.44 \pm 7.021$ & $11.88 \pm 5.98$ & $10.92 \pm 5.832$ & $10.02 \pm 4.457$ & $10.46 \pm 4.4$ & \\
\hline $\begin{array}{l}\text { BSA mean } \pm \text { SD } \\
(\%)\end{array}$ & $23.39 \pm 15.94$ & $23.80 \pm 13.15$ & $22.40 \pm 16.44$ & $25.25 \pm 16.06$ & $23.38 \pm 14.33$ & $17.98 \pm 13.09$ & $18.44 \pm 10.52$ & \\
\hline $\mathrm{BMI}$ mean $\pm \mathrm{SD}$ & $26.12 \pm 3.39$ & $25.88 \pm 3.66$ & $26.68 \pm 2.656$ & $27.89 \pm 2.031$ & $27.16 \pm 3.06$ & $26.77 \pm 2.662$ & $28.33 \pm 1.57$ & \\
\hline $\begin{array}{l}\text { CRP mean } \pm \text { SD } \\
(\mathrm{mg} / \mathrm{dl})\end{array}$ & $5.96 \pm 9.79$ & $4.63 \pm 5.25$ & $9.086 \pm 15.80$ & $15.45 \pm 15.52$ & $9.04 \pm 12.54$ & $6.306 \pm 8.143$ & $5.473 \pm 4.751$ & \\
\hline $\begin{array}{l}\text { ESR mean } \pm \text { SD } \\
(\mathrm{mm})\end{array}$ & $16.83 \pm 13.89$ & $13.50 \pm 9.39$ & $24.35 \pm 19.51$ & $23.28 \pm 18.57$ & $26.13 \pm 14.44$ & $15.77 \pm 9.339$ & $22.76 \pm 11.70$ & \\
\hline $\begin{array}{l}\mathrm{LDL} \text { mean } \pm \text { SD } \\
(\mathrm{mg} / \mathrm{dl})\end{array}$ & $108.30 \pm 28.85$ & $106.0 \pm 27.97$ & $113.7 \pm 30.82$ & $114.9 \pm 23.54$ & $108.5 \pm 29.24$ & $147.4 \pm 7.164$ & $117.8 \pm 26.65$ & \\
\hline $\begin{array}{l}\text { HbAlc } \\
\text { mean } \pm \text { SD (\%) }\end{array}$ & $5.38 \pm 0.47$ & $5.297 \pm 0.446$ & $5.579 \pm 0.46$ & $5.6 \pm 0.59$ & $5.49 \pm 0.55$ & $5.453 \pm 0.151$ & $5.94 \pm 0.226$ & \\
\hline SAF mean \pm SD & $1.89 \pm 0.59$ & $1.665 \pm 0.391$ & $2.431 \pm 0.638$ & $2.037 \pm 0.446$ & $2.059 \pm 0.52$ & $2.093 \pm 0.59$ & $2.213 \pm 0.526$ & $1.816 \pm 0.38$ \\
\hline
\end{tabular}

PsV: patients with chronic plaque psoriasis.

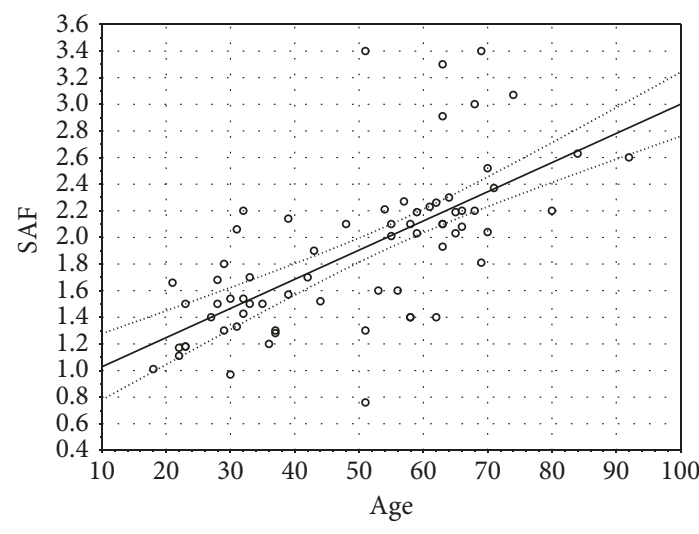

(a)

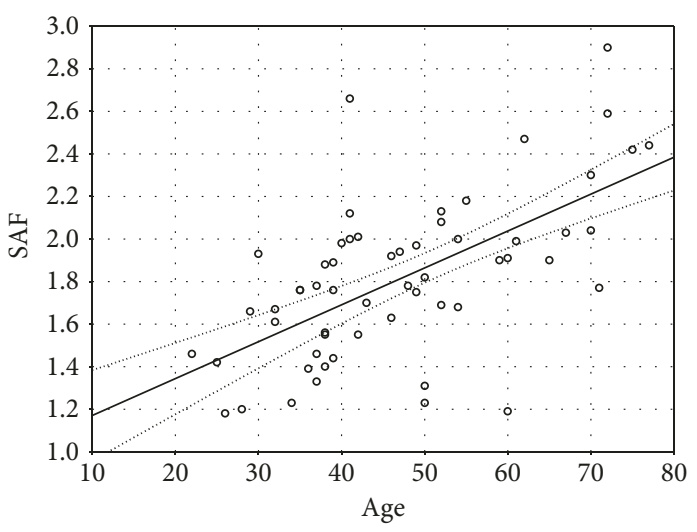

(b)

Figure 1: (a) Significant positive correlations between SAF and age in patients with psoriasis $(R=0.722, p<0.00001)$. (b) Significant positive correlations between SAF and age in controls $(R=0.613, p<0.00001)$.

with elevated levels of CRP compared to controls (2.037 \pm 0.45 vs. $1.816 \pm 0.38 ; p=0.039)$, and this difference was even more significant after adjustment to age $(p<0.00001, Z=$ -19.12) (Figure 2(a)). The mean $\pm S D$ value of ESR in patients with psoriasis was $16.64 \pm 13.90$, and 34 patients had increased ESR (ESR $>12 \mathrm{~mm}$, according to the local laboratory). There was significantly increased SAF in psoriatic patients with increased $\operatorname{ESR}(n=34)$ compared to controls $(2.059 \pm 0.52$ vs. $1.816 \pm 0.38 ; p=0.012)$, and this difference was even more significant after adjustment to age $(p<0.00001, Z=-12.5)$ (Figure 2(b)). There were no significant differences in SAF because of gender, both in patients with psoriasis and controls (Table 3). We did not find any relevant correlations between SAF and severity of skin involvement assessed with PASI and BSA. There was a significant relationship between SAF and BMI in patients with psoriasis $(R=0.297, p=0.0129)$. We did not find any relationship between SAF and BMI in controls. The mean $\pm \mathrm{SD}$ value of $\mathrm{HbA1c}$ in patients with psoriasis was $5.381 \pm 0.47 \%$. Prediabetes was defined as the concentration of $\mathrm{HbA} 1 \mathrm{c}$ from $5.7 \%$ to $6.4 \%(39-46 \mathrm{mmol} / \mathrm{mol})$. Psoriatic patients with prediabetes $(n=22)$ had significantly increased SAF compared to controls $(2.213 \pm 0.53$ vs. $1.816 \pm 0.38 ; p=$ $0.0006)$, and this significant difference remains after adjustment to age ( $p=0.0012, Z=-3.238)$ (Figure 2(c)).

\section{Discussion}

Although psoriasis is generally euglycemic disease, a chronic immune-mediated inflammatory process may lead to the 


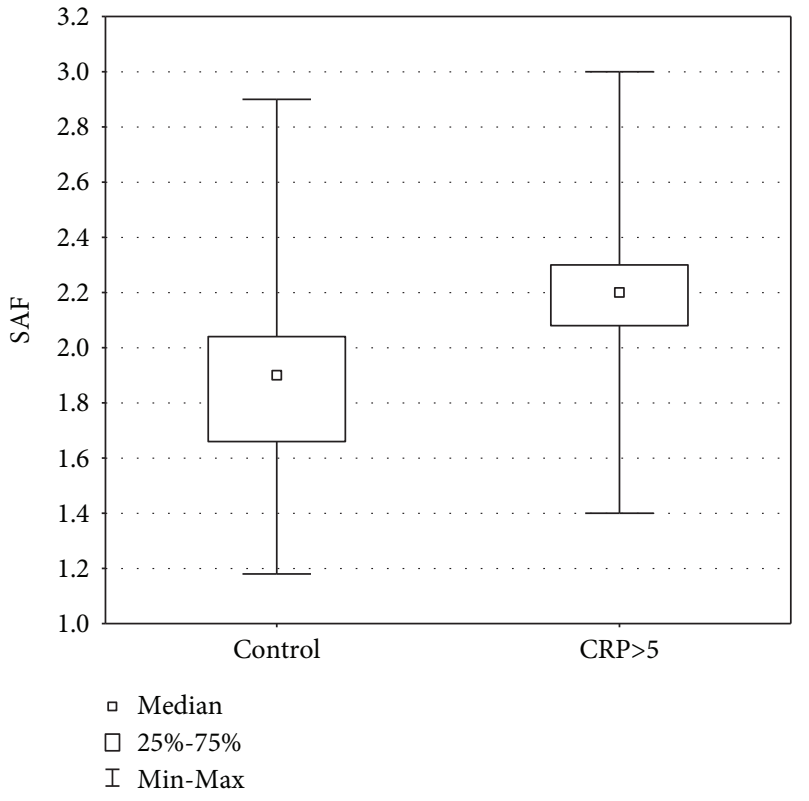

(a)

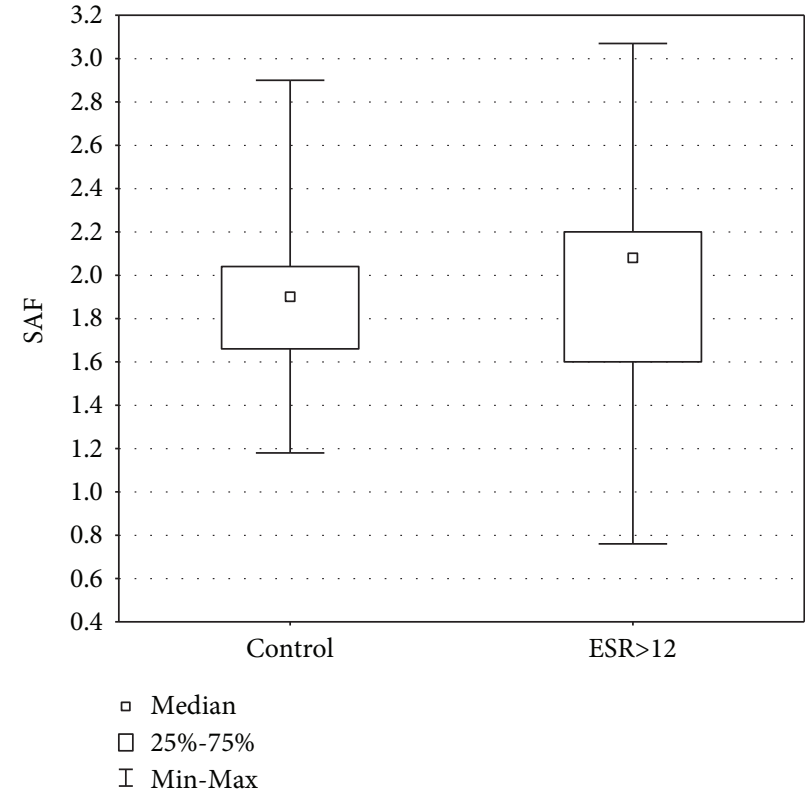

(b)

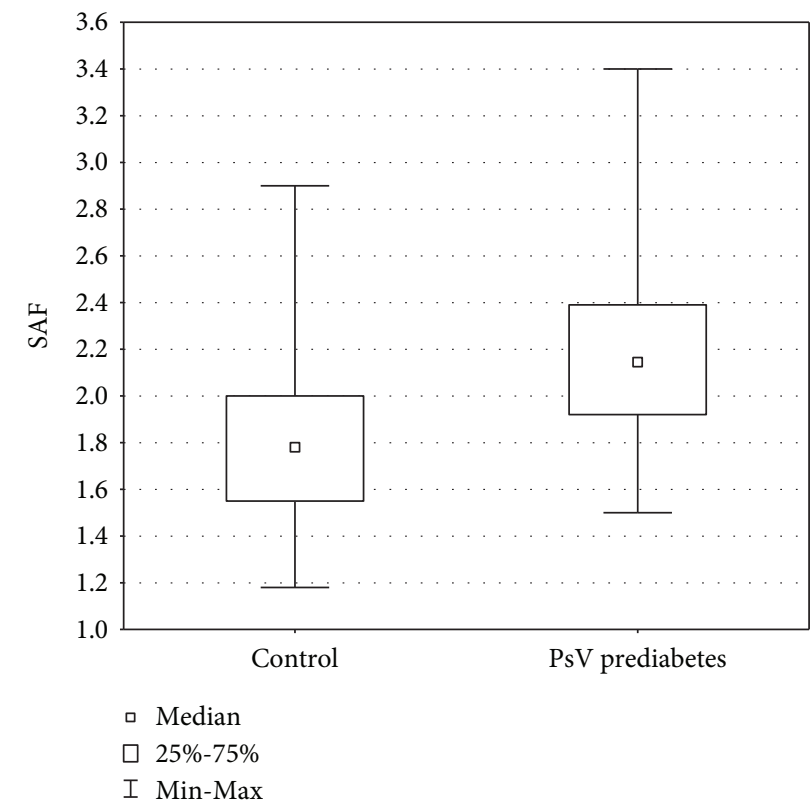

(c)

Figure 2: (a) Increased SAF in patients with psoriasis with elevated CRP levels $(>5 \mathrm{mg} / \mathrm{dl})$ compared to controls $(p<0.00001, Z=-19.120)$. (b) Increased SAF in patients with psoriasis with increased ESR $(>12 \mathrm{~mm})$ compared to controls $(p<0.00001, Z=-12.504)$. (c) Increased SAF in psoriatic patients with prediabetes (HbA1c from $5.7 \%$ to $6.4 \%)$ compared to controls $(p=0.0012, Z=-3.26)$. Data adjusted to the age.

increased AGE accumulation in individuals with psoriasis [26-28]. Increased AGE accumulation has been found in metabolic abnormalities, such as dyslipidemia and diabetes [16-18]. Numerous studies showed increased prevalence of dyslipidemia and diabetes in individuals suffering from psoriasis $[29,30]$. However, to investigate the impact of psoriasis on AGE accumulation more precisely, we excluded from the study psoriatic patients with comorbidities, such as diabetes, dyslipidemia, and obesity. We found positive correlations between SAF and age, both in psoriatic patients and healthy controls. Correlations between SAF and age were previously reported $[31,32]$. Although we did not find any significant difference in SAF between the whole group of patients with psoriasis and controls, we showed that individuals suffering from psoriasis, with elevated CRP levels and increased ESR, had significantly increased SAF as compared to controls. It may suggest the impact of the systemic inflammation on AGE generation and accumulation in individuals with psoriasis. Correlations between SAF and CRP have been previously reported [33]. Furthermore, several studies showed 
TABLE 3: Characteristics of patients with psoriasis according to gender.

\begin{tabular}{|c|c|c|c|}
\hline Characteristic & Patients with psoriasis $(n=70)$ & Patients with psoriasis-male $(n=35)$ & Patients with psoriasis-female $(n=35)$ \\
\hline Age mean $\pm S D$ (years) & $49.33 \pm 17.95$ & $47.82 \pm 16.86$ & $49.94 \pm 18.61$ \\
\hline $\begin{array}{l}\text { Male } n(\%) / \\
\text { female } n(\%)\end{array}$ & $\begin{array}{l}35(50 \%) \\
35(50 \%)\end{array}$ & & \\
\hline $\mathrm{PASI}$ mean $\pm \mathrm{SD}$ & $10.85 \pm 7.07$ & $9.7 \pm 4.452$ & $11.98 \pm 8.069$ \\
\hline $\mathrm{BSA}$ mean $\pm \mathrm{SD}(\%)$ & $23.39 \pm 15.94$ & $21.50 \pm 12.30$ & $25.27 \pm 18.03$ \\
\hline $\mathrm{BMI}$ mean $\pm \mathrm{SD}$ & $26.12 \pm 3.39$ & $26.45 \pm 3.06$ & $25.78 \pm 3.71$ \\
\hline $\mathrm{CRP}$ mean $\pm \mathrm{SD}(\mathrm{mg} / \mathrm{dl})$ & $5.96 \pm 9.79$ & $5.66 \pm 9.114$ & $6.26 \pm 10.54$ \\
\hline $\mathrm{ESR}$ mean $\pm \mathrm{SD}(\mathrm{mm})$ & $16.83 \pm 13.89$ & $16.76 \pm 16.70$ & $16.52 \pm 10.76$ \\
\hline $\mathrm{LDL}$ mean $\pm \mathrm{SD}(\mathrm{mg} / \mathrm{dl})$ & $108.30 \pm 28.85$ & $111.7 \pm 27.91$ & $105.0 \pm 29.78$ \\
\hline $\mathrm{HbAlc}$ mean $\pm \mathrm{SD}(\%)$ & $5.38 \pm 0.47$ & $5.36 \pm 0.49$ & $5.403 \pm 0.447$ \\
\hline SAF mean \pm SD & $1.89 \pm 0.59$ & $1.843 \pm 0.59$ & $1.93 \pm 0.57$ \\
\hline
\end{tabular}

positive correlations between CRP levels and severity of skin involvement in psoriasis [34]. However, in the present study, we did not find such relationship. In the present study, we showed the positive correlation between SAF and BMI in patients with psoriasis. We did not find such a correlation in controls. In previous study, den Engelsen et al. [31] demonstrated higher SAF in nondiabetic obese individuals as compared to controls (nonobese subjects). Fatty tissue, as a source of a wide range of proinflammatory mediators (e.g., IL-6), may contribute to development of systemic inflammation and impact the AGE accumulation in patients with psoriasis. According to the concept of psoriatic march, systemic inflammation in patients with psoriasis subsequently contributes to the insulin resistance, endothelial dysfunction, and increased cardiovascular risk [27]. Increased AGE accumulation may constitute the link between systemic inflammation and increased cardiovascular risk in patients with psoriasis. Furthermore, we analyzed the level of HbA1c in nondiabetic individuals with psoriasis. We showed that individuals with prediabetes had significantly increased SAF as compared to controls.

To the best of our knowledge, this is the first study conducted in Caucasian psoriatic patients with AGE Reader, which is a validated method of SAF measurements. Previously, Yim et al. [35] using EcoSkin fluorescence video dermatoscope found increased autofluorescence in lesional psoriatic skin, significantly correlated with erythema in patients with psoriasis $(n=30)$ from South Korea. In this study, the autofluorescence of nonlesional skin was not increased. Authors did not collect data concerning comorbid conditions and BMI as well as ESR, HbA1c, and LDL levels in the study group. There is difficulty comparing the results because of different study designs and different methods used.

In the present study, we identified factors, such as systemic inflammation, prediabetes, and aging, which may influence enhanced AGE accumulation in individuals with psoriasis without any comorbidities. Increased AGE accumulation may accelerate the atherosclerosis and contribute to increased cardiovascular risk. Therefore, SAF may be considered as a useful, noninvasive method to identify patients with psoriasis at increased cardiovascular risk.

\section{Data Availability}

The data used to support the findings of this study are available from the corresponding author upon request.

\section{Conflicts of Interest}

The authors declare no conflict of interest.

\section{References}

[1] A. J. Smit and H. L. Lutgers, "The clinical relevance of advanced glycation endproducts (AGE) and recent developments in pharmaceutics to reduce AGE accumulation," Current Medicinal Chemistry, vol. 11, no. 20, pp. 2767-2784, 2004.

[2] A. W. Stitt, C. He, S. Friedman et al., "Elevated AGE-modified ApoB in sera of euglycemic, normolipidemic patients with atherosclerosis: relationship to tissue AGEs," Molecular Medicine, vol. 3, no. 9, pp. 617-627, 1997.

[3] K. de Leeuw, R. Graaff, R. de Vries et al., "Accumulation of advanced glycation endproducts in patients with systemic lupus erythematosus," Rheumatology, vol. 46, no. 10, pp. 1551-1556, 2007.

[4] H. Ueno, H. Koyama, S. Tanaka et al., "Skin autofluorescence, a marker for advanced glycation end product accumulation, is associated with arterial stiffness in patients with end-stage renal disease," Metabolism, vol. 57, no. 10, pp. 1452-1457, 2008.

[5] H. L. Nienhuis, K. de Leeuw, J. Bijzet et al., "Skin autofluorescence is increased in systemic lupus erythematosus but is not reflected by elevated plasma levels of advanced glycation endproducts," Rheumatology, vol. 47, no. 10, pp. 1554-1558, 2008.

[6] G. Basta, A. M. Schmidt, and R. De Caterina, "Advanced glycation end products and vascular inflammation: implications for accelerated atherosclerosis in diabetes," Cardiovascular Research, vol. 63, no. 4, pp. 582-592, 2004.

[7] M. F. Weiss, P. Erhard, F. A. Kader-Attia et al., "Mechanisms for the formation of glycoxidation products in end-stage renal disease".

[8] L. de Groot, H. Hinkema, J. Westra et al., "Advanced glycation endproducts are increased in rheumatoid arthritis patients with controlled disease," Arthritis Research \& Therapy, vol. 13, no. 6, article R205, 2011. 
[9] J. L. Wautier and P. J. Guillausseau, "Advanced glycation end products, their receptors and diabetic angiopathy," Diabetes \& Metabolism, vol. 27, pp. 535-542, 2001.

[10] A. M. Schmidt, S. D. Yan, J.-L. Wautier, and D. Stern, "Activation of receptor for advanced glycation end products: a mechanism for chronic vascular dysfunction in diabetic vasculopathy and atherosclerosis," Circulation Research, vol. 84, no. 5, pp. 489-497, 1999.

[11] H. L. A. Nienhuis, J. Westra, A. J. Smit, P. C. Limburg, C. G. M. Kallenberg, and M. Bijl, "AGE and their receptor RAGE in systemic autoimmune diseases: an inflammation propagating factor contributing to accelerated atherosclerosis," Autoimmunity, vol. 42, no. 4, pp. 302-304, 2009.

[12] R. Meerwaldt, T. Links, R. Graaff et al., "Simple noninvasive measurement of skin autofluorescence," Annals of the New York Academy of Sciences, vol. 1043, no. 1, pp. 290-298, 2005.

[13] M. Oleniuc, I. Secara, M. Onofriescu et al., "Consequences of advanced glycation end products accumulation in chronic kidney disease and clinical usefulness of their assessment using a non-invasive technique-skin autofluorescence," Maedica, vol. 6, no. 4, pp. 298-307, 2011.

[14] M. J. Noordzij, J. D. Lefrandt, R. Graaff, and A. J. Smit, "Dermal factors influencing measurement of skin autofluorescence," Diabetes Technology \& Therapeutics, vol. 13, no. 2, pp. 165-170, 2011.

[15] C. da Moura Semedo, M.'. B. Webb, H. Waller, K. Khunti, and M. Davies, "Skin autofluorescence, a non-invasive marker of advanced glycation end products: clinical relevance and limitations," Postgraduate Medical Journal, vol. 93, no. 1099, pp. 289-294, 2017.

[16] R. Meerwaldt, H. L. Lutgers, T. P. Links et al., "Skin autofluorescence is a strong predictor of cardiac mortality in diabetes," Diabetes Care, vol. 30, no. 1, pp. 107-112, 2007.

[17] M. Genevieve, A. Vivot, C. Gonzalez et al., "Skin autofluorescence is associated with past glycaemic control and complications in type 1 diabetes mellitus," Diabetes \& Metabolism, vol. 39, no. 4, pp. 349-354, 2013.

[18] A. J. Smit, J. M. Smit, G. J. Botterblom, and D. J. Mulder, "Skin autofluorescence based decision tree in detection of impaired glucose tolerance and diabetes," PLoS One, vol. 8, no. 6, article e65592, 2013.

[19] A. S. Januszewski, N. Sachithanandan, C. Karschimkus et al., "Non-invasive measures of tissue autofluorescence are increased in type 1 diabetes complications and correlate with a non-invasive measure of vascular dysfunction," Diabetic Medicine, vol. 29, no. 6, pp. 726-733, 2012.

[20] H. L. Lutgers, R. Graaff, T. P. Links et al., "Skin autofluorescence as a noninvasive marker of vascular damage in patients with type 2 diabetes," Diabetes Care, vol. 29, no. 12, pp. 2654-2659, 2006.

[21] A. J. Smit and E. G. Gerrits, "Skin autofluorescence as a measure of advanced glycation endproduct deposition: a novel risk marker in chronic kidney disease," Current Opinion in Nephrology and Hypertension, vol. 19, no. 6, pp. 527-533, 2010.

[22] R. Meerwaldt, J. W. Hartog, R. Graaff et al., "Skin autofluorescence, a measure of cumulative metabolic stress and advanced glycation end products, predicts mortality in hemodialysis patients," Journal of the American Society of Nephrology, vol. 16, no. 12, pp. 3687-3693, 2005.
[23] D. J. Mulder, P. L. van Haelst, R. Graaff, R. O. Gans, F. Zijlstra, and A. J. Smit, "Skin autofluorescence is elevated in acute myocardial infarction and is associated with the one-year incidence of major adverse cardiac events," Netherlands Heart Journal, vol. 17, no. 4, pp. 162-168, 2009.

[24] C. Couppé, C. H. Dall, R. B. Svensson et al., "Skin autofluorescence is associated with arterial stiffness and insulin level in endurance runners and healthy controls-effects of aging and endurance exercise," Experimental Gerontology, vol. 91, pp. 9-14, 2017.

[25] M. G. A. van Eupen, M. T. Schram, T. T. van Sloten et al., "Skin autofluorescence and pentosidine are associated with aortic stiffening: The Maastricht Study," Hypertension, vol. 68, no. 4, pp. 956-963, 2016.

[26] B. B. Davidovici, N. Sattar, P. C. Jörg et al., "Psoriasis and systemic inflammatory diseases: potential mechanistic links between skin disease and co-morbid conditions," The Journal of Investigative Dermatology, vol. 130, no. 7, pp. 1785-1796, 2010.

[27] W. H. Boehncke, S. Boehncke, A. M. Tobin, and B. Kirby, "The 'psoriatic march': a concept of how severe psoriasis may drive cardiovascular comorbidity," Experimental Dermatology, vol. 20, no. 4, pp. 303-307, 2011.

[28] A. Damasiewicz-Bodzek and T. Wielkoszyński, “Advanced protein glycation in psoriasis," Journal of the European Academy of Dermatology and Venereology, vol. 26, no. 2, pp. 172179, 2012.

[29] A. Menter, C. E. Griffiths, P. W. Tebbey, E. J. Horn, W. Sterry, and on behalf of the International Psoriasis Council, "Exploring the association between cardiovascular and other diseaserelated risk factors in the psoriasis population: the need for increased understanding across the medical community," Journal of the European Academy of Dermatology and Venereology, vol. 24, no. 12, pp. 1371-1377, 2010.

[30] A. D. Cohen, J. Dreiher, Y. Shapiro et al., "Psoriasis and diabetes: a population-based cross-sectional study," Journal of the European Academy of Dermatology and Venereology, vol. 22, no. 5, pp. 585-589, 2008.

[31] C. den Engelsen, M. van den Donk, K. J. Gorter, P. L. Salomé, and G. E. Rutten, "Advanced glycation end products measured by skin autofluorescence in a population with central obesity," Dermato-Endocrinology, vol. 4, no. 1, pp. 33-38, 2012.

[32] N. Botros, D. Sluik, R. P. van Waateringe, J. H. M. de Vries, A. Geelen, and E. J. M. Feskens, "Advanced glycation endproducts (AGEs) and associations with cardio-metabolic, lifestyle, and dietary factors in a general population: the NQplus study," Diabetes/Metabolism Research and Reviews, vol. 33, no. 5, 2017.

[33] M. Nagano, K. Fukami, S. I. Yamagishi et al., "Tissue level of advanced glycation end products is an independent determinant of high-sensitivity C-reactive protein levels in haemodialysis patients," Nephrology, vol. 16, no. 3, pp. 299303, 2011.

[34] K. H. Yiu, C. K. Yeung, H. T. Chan et al., "Increased arterial stiffness in patients with psoriasis is associated with active systemic inflammation," British Journal of Dermatology, vol. 164, no. 3, pp. 514-520, 2011.

[35] J. H. Yim, K. H. Jeong, and M. K. Shin, "Comparative study of skin autofluorescence expression in atopic dermatitis and psoriasis: a prospective in vivo study," Skin Research and Technology, vol. 23, no. 2, pp. 169-175, 2017. 


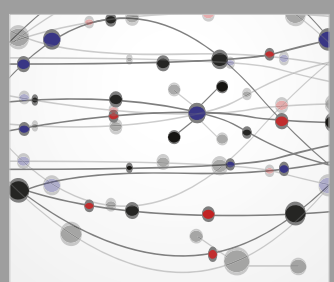

The Scientific World Journal
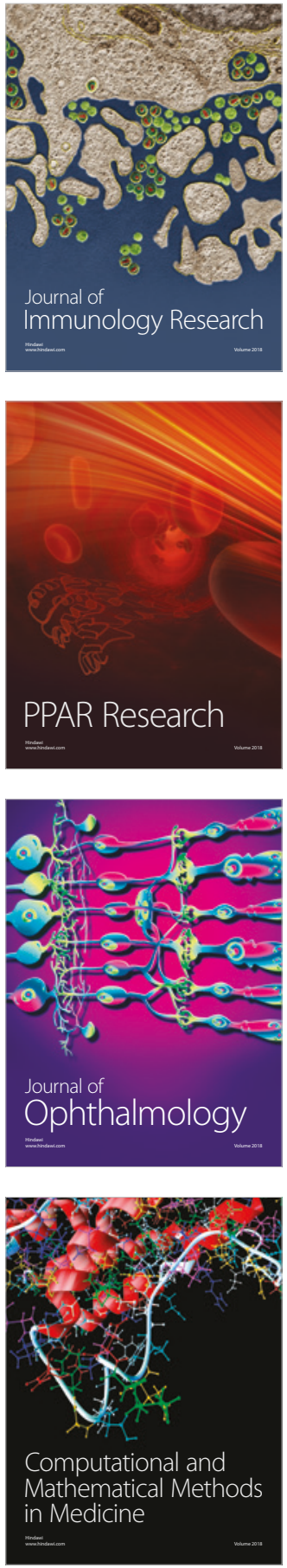

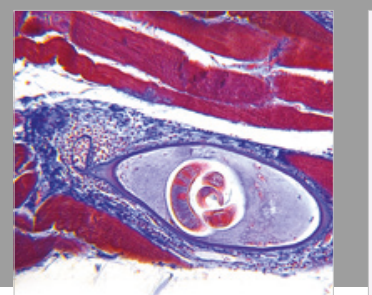

Gastroenterology Research and Practice

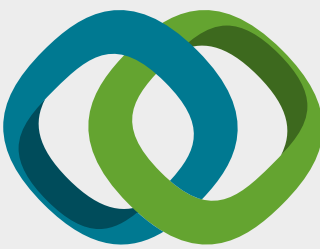

\section{Hindawi}

Submit your manuscripts at

www.hindawi.com
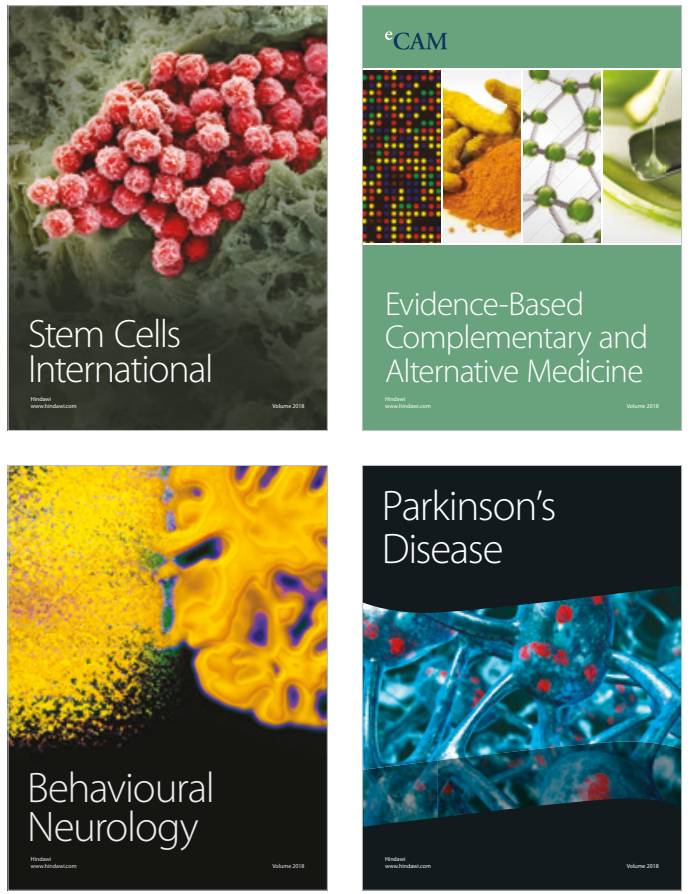

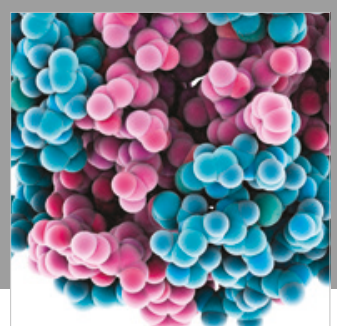

ournal of

Diabetes Research

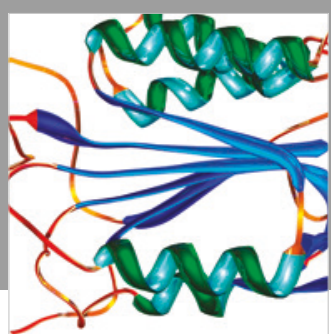

Disease Markers
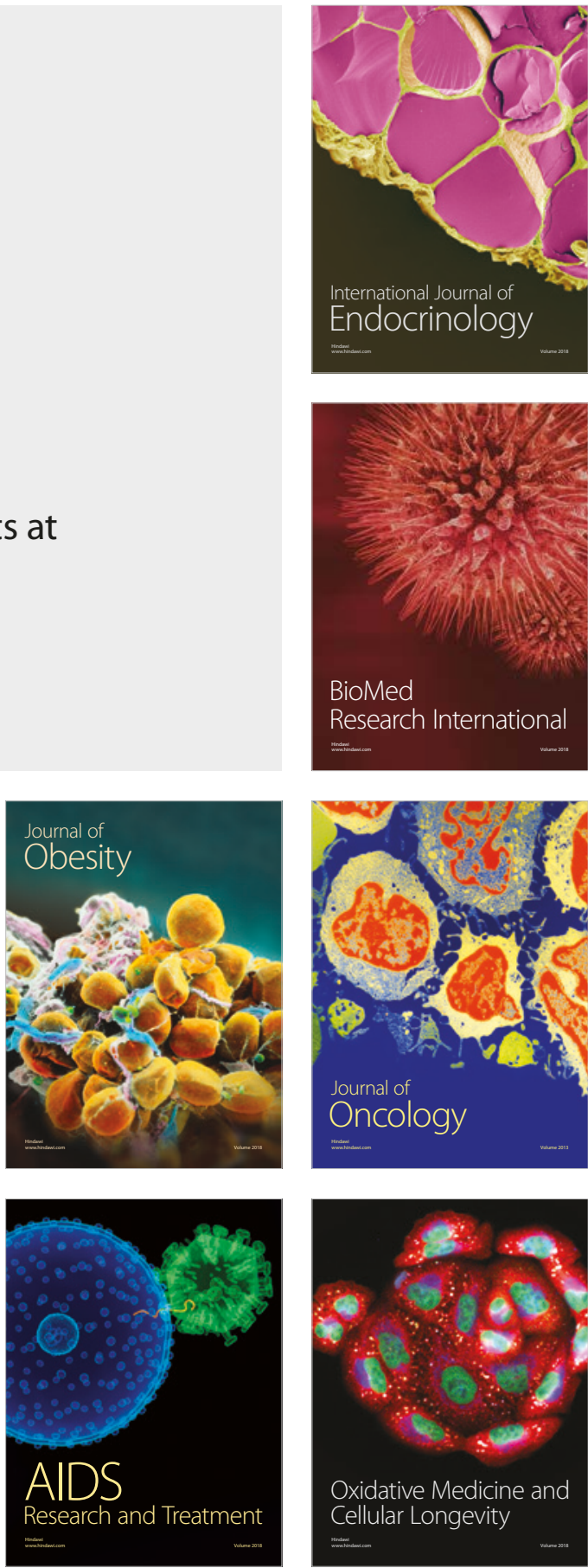